\title{
Influence of various factors on individual radiation exposure from the chernobyl disaster
}

\author{
Pavlo Zamostian1, Kirsten B Moysich², Martin C Mahoney², \\ Philip McCarthy ${ }^{2}$, Alexandra Bondar ${ }^{1}$, Andrey G Noschenko ${ }^{1}$ and \\ Arthur M Michalek*2
}

\begin{abstract}
Address: ${ }^{1}$ National University "Kyiv Mogila Academy" Department of Environment Sciences, Kyiv, Ukraine and ${ }^{2}$ Roswell Park Cancer Institute, Buffalo, New York, USA

E-mail: Pavlo Zamostian - pvzamos@ukr.net; Kirsten B Moysich - kirsten.moysich@roswellpark.org; Martin C Mahoney - martin.mahoney@roswellpark.org; Philip McCarthy - philip.mccarthy@ roswellpark.org;

Alexandra Bondar - bon@bon.kiev.ua; Andrey G Noschenko - bon@bon.kiev.ua; Arthur M Michalek* - arthur.michalek@roswellpark.org

${ }^{*}$ Corresponding author
\end{abstract}

Published: 29 October 2002

Environmental Health: A Global Access Science Source 2002, I:4

This article is available from: http://www.ehjournal.net/content/I/I/4

(C) 2002 Zamostian et al; licensee BioMed Central Ltd. This article is published in Open Access: verbatim copying and redistribution of this article are permitted in all media for any purpose, provided this notice is preserved along with the article's original URL.
Received: 18 July 2002

Accepted: 29 October 2002

\begin{abstract}
Background: The explosion at the Chernobyl Nuclear Power Plant was one of the greatest known nuclear disasters of the 20th century. To reduce individual exposure to ionizing radiation the Soviet Union government introduced a number of counter-measures. This article presents a description of how historical events conspired to disrupt these efforts and affect residents in exposed areas.
\end{abstract}

Methods: This study employed an extensive review of data on radionuclide deposition, contamination patterns and lifestyle characteristics. Data were obtained from the Ukraine Ministry of Health and the Ukraine Research Center for Radiation Medicine.

Results: Data are presented on annual contamination rates in selected locales as well as data on local food consumption patterns. Historical factors including economic and political circumstances are also highlighted. Results show the diminution of individual doses between I987 and I99I and then an increase between 199 I and 1994 and the relationship between this increase and changes in the lifestyle of the local population.

Conclusion: A number of factors played direct and indirect roles in contributing to the populace's cumulative radiation exposure. Future post-contamination studies need to consider these factors when estimating individual exposures.

\section{Background}

The Chernobyl Nuclear Power Plant accident can be differentiated from other radiation accidents not only by its magnitude but also by its transcontinental impact and the unique patterns of radionuclide fallout. It is estimated that more than four million people in the Ukraine alone were exposed. Unlike the atomic bomb detonation, exposures from Chernobyl were different and subtler [1]. Rather than high-energy external exposure, the vast majority of individuals received on-going, low-dose exposures owing 


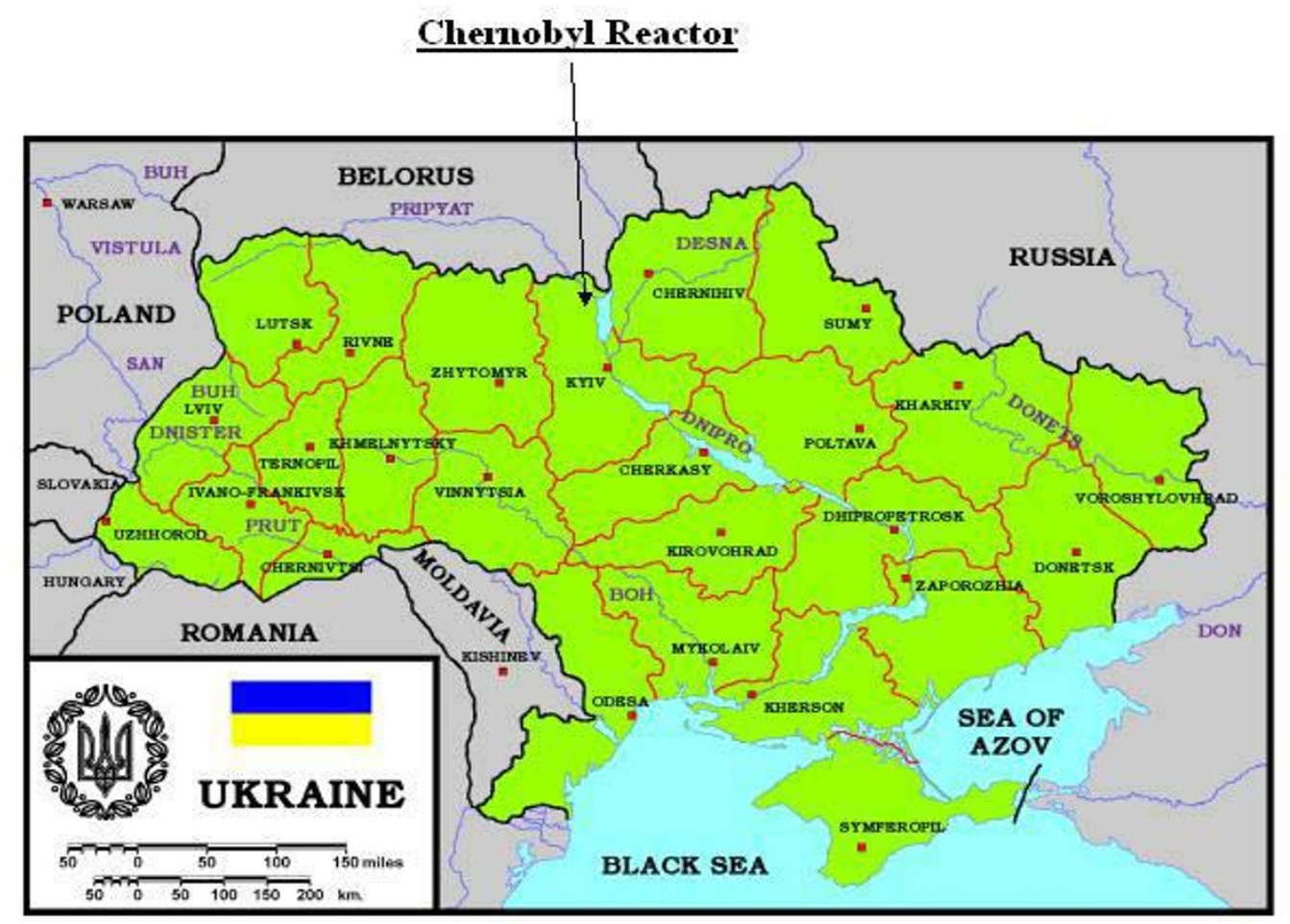

Figure I

Map of Ukraine showing Oblasts in relation to the Chernobyl Nuclear Power Plant

to the presence of long-lived radionuclides such as cesium (Cs), strontium (Sr) and plutonium (Pu) in their food supply. These exposures and the government's response to minimize their effect were further complicated by the interplay of economic and political factors resulting from the dissolution of the Soviet Union.

This report describes the dynamics of these factors in a specific region of Ukraine where the population received significant internal doses of radiation due to consumption of radioactively contaminated food and where these exposures, and thereby their health risks, appear to have been exacerbated by the dissolution of the Soviet Union and subsequent disruption of protective counter-measures.

\section{Characteristics of the study region}

Fallout from the Chernobyl Nuclear Power Plant accident contaminated vast regions of the Ukraine. The territories of the "Ukrainian Polissia" region of Ukraine were among those most affected. These rayons*, located at the northern part of the Kyiv, Zhitomir and Rivno Oblasts, span over 50,000 square kilometers and are home to over 1.7 million people (Figure 1). The Polissia territories are known for their great variations in environmental and geographic conditions as well as in agricultural patterns. Radioactive contamination within these territories (excluding the more highly contaminated 30-km exclusion zone) may be characterized by levels of ${ }^{137} \mathrm{Cs}$ ground deposition densities of up to $555 \mathrm{kBq} \cdot \mathrm{m}^{-2}$ (local spots up to $3700 \mathrm{kBq} \cdot \mathrm{m}^{-2}$ ); ${ }^{90} \mathrm{Sr}$ depositions generally did not exceed $100 \mathrm{kBq} \cdot \mathrm{m}^{-2}$; and ${ }^{238-240} \mathrm{Pu}$ depositions did not exceed $370 \mathrm{kBq} \cdot \mathrm{m}^{-2}[2]$.

\section{Local contamination}

The Rivno Oblast, located approximately 250-300 km from the Chernobyl Nuclear Power Plant, is one of the more interesting areas within the Ukrainian Polissia. Levels of ${ }^{137} \mathrm{Cs}$ soil deposition did not exceed $200 \mathrm{kBq} \cdot \mathrm{m}^{-2}$, and levels of ${ }^{90} \mathrm{Sr}$ and ${ }^{238-240} \mathrm{Pu}$ depositions were negligible. Because of these "low" levels of exposure, this area was not officially considered "radioactively contaminated" by the Chernobyl accident. Detailed studies of this area, therefore, were not begun until 1987-1988, when 
Table I: Radioactive contamination of the Rokitnovsky Rayon, Rivno Oblast

\begin{tabular}{lllll}
\hline Soil deposition & Mean, $\mathrm{kBq} \cdot \mathrm{m}^{-2}$ & $\begin{array}{l}\text { Standard deviation, } \\
\mathrm{kBq} \cdot \mathrm{m}^{-2}\end{array}$ & Maximum, $\mathrm{kBq} \cdot \mathrm{m}^{-2}$ & Minimum, $\mathrm{kBq} \cdot \mathrm{m}^{-2}$ \\
\hline${ }^{137} \mathrm{Cs}$ & 74,3 & 32,2 & 170,2 & 25,9 \\
${ }^{90} \mathrm{Sr}$ & 4,5 & 5,5 & 23,3 & 0,4 \\
${ }^{238-240} \mathrm{Pu}$ & 0,037 & 0,027 & 0,14 & 0,0 \\
\hline
\end{tabular}

Source: Ministry of Health, 199513

unusually high levels of ${ }^{137} \mathrm{Cs}$ were detected transferring from soil to plants and through the ecological chain to animals and people. The local environment also has peatswampy soil that is characterized by the highest values of soil-to-milk transfer coefficients.

In addition, the rayons of the Rivno Oblast may be characterized by unique socioeconomic characteristics and farm-management practices. Residents tend to live in small villages surrounded by forests. Family size tends to be moderately large ( 3 to 5 children). The main food sources are locally produced (vegetables, milk) and/or include foods that can be foraged from the forests (mushrooms, berries and wild game) and swamps (cranberries). These wild foods are known to most readily concentrate radioactive elements (particularly ${ }^{137} \mathrm{Cs}$ ). It is estimated that approximately 90 percent of the total lifetime radiation dose to individuals in the population is due to internal exposure to radiation from radiocesium ingested in contaminated foodstuffs [3].

\section{Methods}

\section{Radiation exposure measurements and dose estimates}

The Rokitnovsky rayon, which is located within the Rivno Oblast, was selected for this study because it is well described by the above characteristics. Moreover, an array of personal and environmental radiation monitoring data are available for this area from the Radiation Protection Institute [4]. Table 1 summarizes the data on radioactive contamination of Rokitnovsky due to the Chernobyl accident.

An individual's dose is calculated based on external (direct exposure) and internal exposures (i.e., consumption of milk and wild foods). Of particular interest in this discussion is internal exposure. It is possible to estimate internal exposures from radiocesium ingestion within a particular population by considering the concentration of $137 \mathrm{Cs}$ in the human diet over different periods of time [3]. This concentration is determined by the radioecological conditions at the place where the foodstuffs were produced (137Cs soil deposition and its soil-transfer factor) and dietary patterns (i.e., frequency, quantity of particular foodstuffs such as milk, mushrooms, etc.).

Radiological monitoring for internal exposure may be accomplished in two ways: 1) monitoring of radionuclide body burden by whole body counters (WBCs); or 2) monitoring of radionuclide concentrations in various foodstuffs and their reported consumption. Continuous WBCs of radiocesium body burden across gender and among different age groups and seasons of year is the most accurate way to estimate internal exposure $[4,5]$, but surveillance is often complicated and time consuming. While measurement of radiocesium concentration in locally produced foodstuffs provides information on the relative contribution of specific food items, it is quite difficult to determine individual values and often impractical.

\section{Contamination of locally produced milk}

In the Ukrainian population, milk is widely consumed by both children and adults since it is readily available throughout the year in all areas. Milk is also a significant source of internal exposure due to its concentration of radiocesium. According to the results of dietary studies in the northern part of Rivno Oblast $[4,6]$ approximately $70-75 \%$ of daily ${ }^{137} \mathrm{Cs}$ intake is due to consumption of locally produced milk and milk products; about $10-15 \%$ may be attributed to forest mushroom and berry consumption and about $10-15 \%$ due to potato and vegetable consumption. Thus, consumption of locally produced milk appears to represent the most important factor in determining internal radiocesium exposure. Although forest mushrooms and berries are highly contaminated with ${ }^{137} \mathrm{Cs}$, most of the internal exposure resulted from milk consumption due to the prevalence of milk consumption in this population.

\section{Countermeasures}

A number of countermeasures were initiated after the Accident. The goal of these activities was to reduce the population's internal exposure to radionuclides such as ${ }^{131}$ I in the short-term and ${ }^{137} \mathrm{Cs}$ in the long-term. The most significant countermeasures included governmental prohibi- 


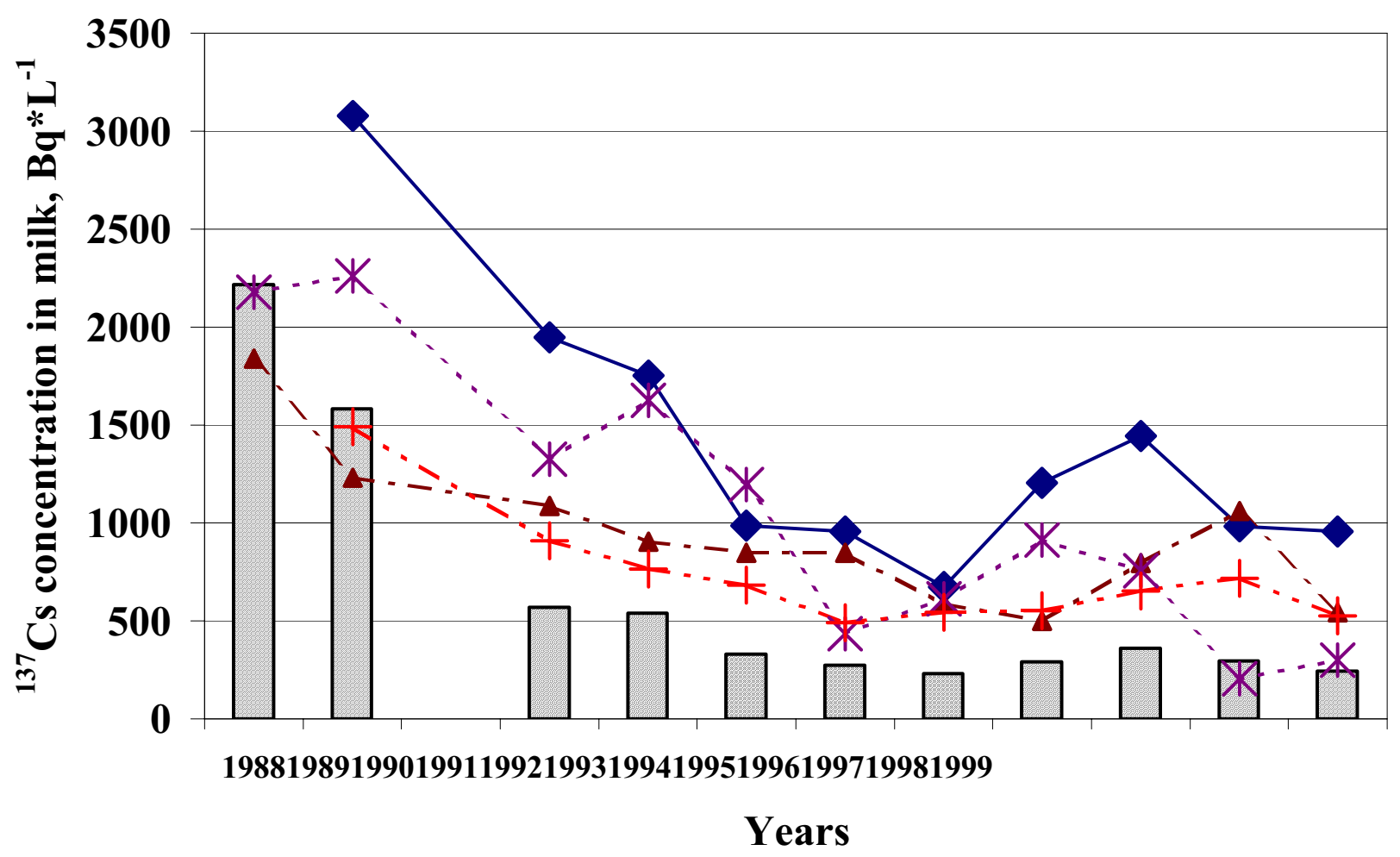

\begin{tabular}{|c|c|}
\hline $\begin{array}{l}\square \text { Rokitnovsky } \\
-*-* \text { Perehodichi }\end{array}$ & $\begin{array}{l}\longrightarrow \text { Vezhitsia } \\
-+- \text { St. Selo }\end{array}$ \\
\hline
\end{tabular}

Figure 2

Dynamics of ${ }^{137} \mathrm{Cs}$ concentration in milk (Bq-L), produced on private farms in selected villages, Rokitnovsky Rayon, Rivno Oblast, Ukraine

tions of consuming locally produced milk and foodstuffs, warnings against consumption of wild foods (mushrooms and berries) use of "clean areas" for farming and pastures where improvements had been applied and application of Cs binders to animal foods. In addition, the government distributed foods from uncontaminated areas to the residents of contaminated areas. The success of these counter measures was likely non-uniform and varied by oblast as well as by type of farm (collective vs. private). The long-term success of this strategy depended on continuous governmental support and compliance among residents within the affected areas. According to a report by the International Atomic Energy Agency (IAEA), the application of countermeasures led to significant reductions in radiocesium contamination of milk and meat produced on State and collective farms [7]. They note, however, that many of the countermeasures were difficult to apply by small-scale farmers for economic reasons thus affording significant proportions of the population with little protection.

\section{Results}

Ionizing radiation exposure assessment or biomonitoring Figure 2 illustrates results of ${ }^{137} \mathrm{Cs}$ concentrations in milk from 1988 through 2000 in Rokitnovsky. In excess of 5000 gamma-spectrometry measurements of milk were conducted during this period. Milk samples were collected from privately owned cows by the Ukrainian government as part of a radiological monitoring program within areas contaminated by the Chernobyl accident. Milk samples from privately owned cows were tested because milk is a significant dietary staple of these individuals and is known to concentrate Cs.

In the selected settlements of Vezhitsia, Drozdyn, Perehodichi and Stare Selo approximately 20-80 milk sam- 
ples were collected each year during pasture season (spring through autumn). Concentration of ${ }^{137} \mathrm{Cs}$ and ${ }^{134} \mathrm{Cs}$ was determined in these milk samples by means of gamma-spectrometry measurements. As demonstrated by Figure 2, while there is variation in the concentration of ${ }^{137} \mathrm{Cs}$ in milk in different areas of the Rokitnovsky region, there is a significant decline in ${ }^{137} \mathrm{Cs}$ milk concentrations over time. The former may be attributed to a number of factors such as the actual radioactive contamination of the territory (Table 1) as well as differences in environmental conditions (soil types, landscapes, etc.) that affect the transfer of ${ }^{137} \mathrm{Cs}$ from the soil. For example, the transfer factor of ${ }^{137} \mathrm{Cs}$ from soil to milk in 1991-1992 was in the range from 0.3 to $20 \mathrm{~Bq} \cdot \mathrm{L}^{-2}$ per $\mathrm{kBq} \cdot \mathrm{m}^{-2}$.[8]. The soil transfer factor is the most important parameter in determining ${ }^{137} \mathrm{Cs}$ concentration in locally produced milk. The villages of Vezhitsia, Drozdyn, Perehodichi and Stare Selo exhibited the highest soil-to-milk transfer coefficients. For 1991-1992, recorded values were $19.9 \mathrm{~Bq} \cdot \mathrm{L}^{-2} \mathrm{per} \mathrm{kBq} \cdot \mathrm{m}^{-}$ 2 in Vezhitsia, $19.4 \mathrm{~Bq} \cdot \mathrm{L}^{-2}$ per $\mathrm{kBq} \cdot \mathrm{m}^{-2}$ in Drozdyn, 9.9 $\mathrm{Bq} \cdot \mathrm{L}^{-2}$ per $\mathrm{kBq} \cdot \mathrm{m}^{-2}$ in Perehodichi and $17.4 \mathrm{~Bq} \cdot \mathrm{L}^{-2}$ per $\mathrm{kBq} \cdot \mathrm{m}^{-2} \mathrm{~Bq}-\mathrm{L}^{-2}$ in Stare Selo. High transfer factors coupled with other local characteristics (e.g., proximity to forests and swamps, availability of cultivated pastures for cows) make these areas the most critical from the standpoint of internal exposure in nearby residents. From 1988 through 1991, the mean concentration in milk (for all of Rokitnovsky) decreased by more than 4 fold and by 1996 nearly 10-fold. Decrements of similar magnitude have been reported by other investigators $[9,10]$. No further decrease was observed for the period 1996 through 2000. Given that milk is an important contributor of radiocesium intake for rural people as previously described, decreases in environmental contamination levels would be paralleled by decreases in the local population's internal dose.

\section{Whole body counts}

Beginning in 1987, the Ukrainian government-monitoring program in the radioactively contaminated areas initiated direct body burden measurements of radiocesium using WBCs among Rokitnovsky residents [4]. About 16,000 WBCs were performed among different age groups, with approximately 7000 measurements among adults. The majority of these were performed in the field by the Research Center for Radiation Medicine (RCRM) using mobile whole body counters while some were performed in the central laboratory at the RCRM in Kiev. Regardless, all measurements were made using similar methodology and are considered equally valid. It should be noted that the number of measurements performed each year did vary. Individuals were selected from each settlement. The typical annual number of measurements in each settlement was 50-100, which corresponds to 10$20 \%$ of the adult population in each settlement. However there were some years when only 10 measurements were made in a given settlement while in other years 300-400 measurements were made.

Mean annual effective doses calculated based on results of WBC measurements between 1988 and 2000 are presented in Figure 3. As can be seen, there is great variation among annual internal effective doses $\left(D_{\text {int }}\right)$ of radiation from ingested radiocesium. $\mathrm{D}_{\text {int }}$ depends on two main radioecological parameters - the value of ${ }^{137} \mathrm{Cs}$ deposition in soil and the soil-to-milk transfer factor. Annual effective doses through internal exposure $\left(D_{\text {int }}\right)$ appear higher in these selected villages (Vezhitsia, Drozdyn, Perehodichi and Stare Selo) compared to the mean value for the whole Rayon. From 1988 until 1991, $D_{\text {int }}$ decreased 2-4 fold; then between 1992 and 1994 there was a rapid increase of $\mathrm{D}_{\text {int }}$ followed by a slight reduction (1995) and then a stabilization of dose (1996-2000). However, for selected villages (especially in Stare Selo and Vezhitsia), there are annual variations with no discernable pattern of decreasing doses. These observations warrant further investigation to clarify the roles played by the application of counter-measures, lifestyle changes, elimination of radionuclides from the ecosystem and/or other unmeasured factors.

\section{Modifying factors}

A myriad of factors are known to contribute to individual Chernobyl-related ionizing radiation exposure. Chief among these is direct environmental contamination from the accident based on prevailing wind patterns, type of housing, amount of time spent outdoors, etc. Other factors include those that affect levels of internal exposure such as soil types (soil-to-milk transfer factors) and consumption patterns of contaminated foods (locally produced and wild). While these factors directly contribute to individual exposures, they are also subject to the influence of external forces. The confluence of economic (collapse of the Soviet Union in 1991), environmental (fallout patterns and local soil-to-milk transfer ratios) and sociological (local food consumption patterns) factors resulted in significant variations in individual exposure.

Radionuclide fallout from the Chernobyl reactor explosion and the ensuing graphite fire contaminated vast areas of land, most of which was agricultural. The immediate governmental response was the destruction of livestock and food crops within the contaminated areas. Countermeasures were then introduced by the Soviet Union government that included shipments of uncontaminated milk and foods into these areas so as to reduce individual exposure and associated health risks. If these countermeasures were not introduced and people continued to consume locally produced foodstuffs, levels of $\mathrm{D}_{\text {int }}$ of ${ }^{137} \mathrm{Cs}$ would have continued unabated and the populace's 


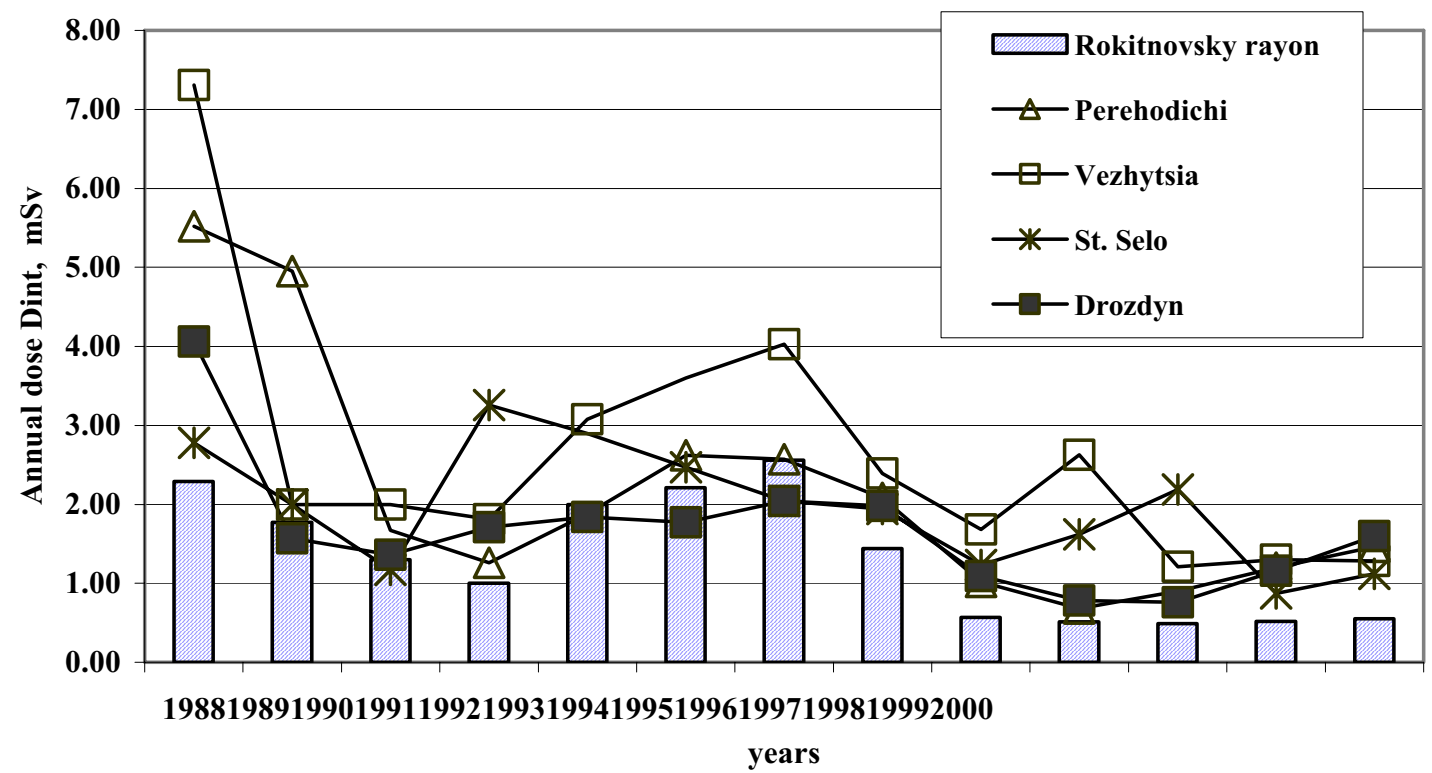

Figure 3

Dynamics of annual effective doses of internal exposure $\left(D_{\text {int }}\right)$ due to ${ }^{137} C$ s ingestion in Rokitnovsky Rayon and selected village, Rivno Oblast, Ukraine by year from Whole Body Count (WBC) data

only hope would have been time, the time it would take for the natural elimination of ${ }^{137} \mathrm{Cs}$ from the ecosystem. And time is not an ally. While the half-life of ${ }^{137} \mathrm{Cs}$ in agricultural products is $2.8-5.6$ years, it is approximately 10 years for berries and 20 years for mushrooms [11]. Fesenko, et al.[12] studied twenty-seven rural settlements to assess the effectiveness of countermeasures. They observed an initial decrease of up to $40 \%$ of doses with a gradual diminution of effect over time.

\section{Discussion}

Introduction of countermeasures such as the provision of non-contaminated foodstuffs from 1988 until 1991, resulted in decreases of ${ }^{137} \mathrm{Cs}$ exposures based upon biomonitoring and WBC data in the Rokitnovsky Rayon by more than two-fold. Similar decreases were documented in other villages, such as in Perehodichi and Vezhitsia, where levels dropped nearly four fold. After the collapse of the Soviet Union in 1991, values of $D_{\text {int }}$ in these areas rapidly increased and approximated values registered in the immediate post-accident period.

A plausible explanation for the increase in $\mathrm{D}_{\text {int }}$ relates to the severe economic strains brought on by the dissolution of the Soviet Union and a cessation of government sponsored counter-measures. The collapse of the FSU, which was accompanied by high unemployment and economic hardship, led to a reversion to traditional diets. People were forced to once again consume more locally produced food as well as "free" natural foods from the forests (mushrooms, berries, wild game, etc.). Moreover, after a relatively short period of time, it is likely that people became indifferent to warnings of the possible harm from radiation and to recommendations about the consumption of these foods. The influence of these factors is especially strong in those villages located in the forest area, where wild foods are a traditional mainstay of the local diet. Radiological contamination is tasteless, odorless and invisible. It is only natural that after the "immediate" crisis passed more people were more concerned with the immediate effects of hunger rather than any possible longterm health effects.

Further evidence to support this hypothesis can be gleaned from interviews conducted by one of the authors (PZ) among a sample of residents of the northern rayons of the Rivno Oblast covering the period 1987 and 1994 (retrospectively collected by PZ). Families were asked whether they consumed the following foods: home milk and milk products, vegetables, potatoes, home meat, mushrooms and berries from the forest, local fish and wild game (Figure 4). Results indicate that for 1994, more 


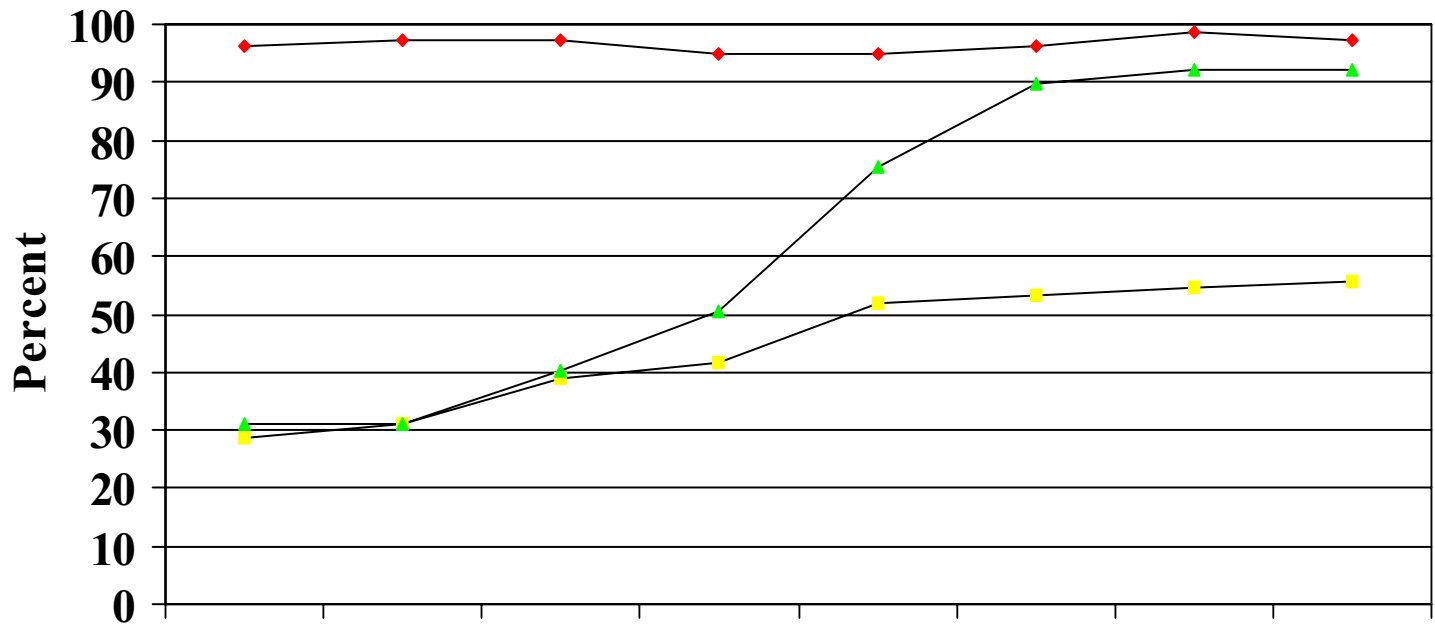

19871988198919901991199219931994

$$
\rightarrow-\text { Milk -- Mushrooms }-- \text { Berries }
$$

Figure 4

Percentage Reporting Consumption of Local Foodstuffs Among Residents of Rivno Oblast by Year

people reported consuming such potentially highly contaminated products as mushrooms and forest berries compared to 1987 . For example, only $31 \%$ of those interviewed in 1987 reported eating forest berries compared to $92 \%$ in 1994 . For wild mushrooms, $29 \%$ reported consumption in 1987 compared to $44 \%$ in 1994 . However, the proportion reporting consumption of milk (97\%), potatoes $(98 \%)$ and vegetables $(97 \%)$ remained constant over time (data not shown in Figure). It should be noted that in most of the territories with high levels of ${ }^{137} \mathrm{Cs}$ contamination (i.e., those where external exposure $>$ internal exposure), about $40 \%$ of the dose was received during the first year following the accident and about $60 \%$, owing to internal exposures, during the next five to seven years with relatively little received thereafter [13].

\section{Conclusions}

We have related how a number of factors contributed to individual exposures among residents of the Polissia Region in Ukraine. Contrary to initial expectations that food management practices, effective counter-measures, and time would result in decreased internal exposure from ${ }^{137} \mathrm{Cs}$, this did not occur possibly due to social and economic forces active in the study region. The economic crisis that occurred in the Ukrainian part of the Former Soviet Union after 1990 likely contributed to increased internal doses from ${ }^{137} \mathrm{Cs}$ owing to consumption of locally produced and wild foods (mushrooms, berries, wild game, etc.).

In the absence of serial WBCs, individual exposure can only be estimated based on environmental sampling and personal interviews. Future post-contamination studies need to include continuous monitoring of both the radiation content of locally produced foodstuffs and patterns of consumption. Moreover, efforts should include periodic population surveys to assess changes in dietary behaviors, agricultural practices, politico-economic issues, and other factors that could affect internal dose estimates. Only on the basis of such information will it be possible 
to reasonably plan, implement and evaluate effective protective programs aimed at reducing exposures and to affect the subsequent risk of morbidity and mortality.

\section{List of Abbreviations}

Bq: Becquerel Cs :Cesium

$\mathrm{D}_{\text {int }}:$ Internal effective doses

IAEA: International Atomic Energy Agency

I: Iodine

Pu: Plutonium

RCRM: Research Center for Radiation Medicine

\section{Sr: Strontium}

WBC: Whole body count

\section{Competing interests}

None declared.

\section{Authors' contributions}

PZ and AGN participated in statistical analysis and drafting the manuscript. MCM, PM, and $\mathrm{AB}$ participated in study design and manuscript preparation. KBM and AMM conceived of the study and participated in its design and manuscript preparation.

\section{Note}

* The Ukraine consists of 24 large administrative units Oblasts and the Republic of Crimea. Each Oblast consists of smaller administrative units called Rayons.

\section{Acknowledgements}

"This work was supported by Grant \#N000 I4-94-I-0049 issued to Georgetown University from the Office of Naval Research in support of the International Consortium for Research on the Health Effects of Radiation. The contents are solely the responsibility of the authors and do not necessarily represent the Office of Naval Research or Georgetown University."

\section{References}

I. Weinberg AD, Kripalani S, McCarthy PL, Schull W]: Caring for survivors of the Chernobyl disaster. What the clinician should know. Jama 1995, 274:408-12

2. Ten years after the accident at Chernobyl NPP. Ukraine national report. Kiev: Ministry of Chernobyl of Ukraine 1996

3. United Nations Scientific Committee on the Effects of Atomic Radiation: Exposures and Effects of the Chernobyl Accident. In: Sources and Effects of lonizing Radiation Volume II Effects United Nations Press 2000, 485

4. Likhtarev IA, Kovgan LN, Vavilov SE, Gluvchinsky RR, Perevoznikov ON, Litvinets LN, Anspaugh LR, Kercher JR, Bouville A: Internal exposure from the ingestion of foods contaminated by I37Cs after the Chernobyl accident. Report I. General model: ingestion doses and countermeasure effectiveness for the adults of Rovno Oblast of Ukraine. Health Phys 1996, 70:297-317

5. Perevoznikov ON, Likhtarev IA, Litvinets LA, Jakovleva G: Experience, problems and results of mass implementation of whole-body counters at post-Chernobyl period. In: Assessment of the health and environmental impact from radiation doses due to released radionuclides: proceedings of an international workshop at Chiba; Chiba 1994, 129-139

6. Korzun VN, Stepanova El, Torbin VF: lonizing radiation and child nutrition. Kiev: Chornobylinterinform 1997

7. Guidelines for Agricultural Countermeasures following an Accidental Release of Radionuclides: IAEA Technical Reports Series, No. 3631994

8. Dosimetry passportization of the settlements of Ukraine located at the territories radioactively affected after Chernobyl accident, Catalog 5. Kiev: Ministry for health protection of Ukraine; (in Russian) 1995

9. Sanzharova NI, Fesenko SV, Aleksahin RM, Anisimov VS, Kuznetsov LG, Chernyaeva LG: Changes in the forms of I37Cs and its availability for plants as dependent on properties of fallout after the Chernobyl nuclear power plant accident. Sci Total Environ 1994, 154:9-22

10. Muck K: Longterm reduction of caesium concentration in milk after nuclear fallout. Sci Total Environ 1995, 162:63-73

II. Shutov VN, Bruk GY, Basalaeva LN, Vasilevetskiy VA, Ivanova NP, Karlin IS: The role of mushrooms and berries in the formation of internal exposure doses to the population of Russia after the Chernobyl Accident. Rad Prot Dos 1996, 67:55-64

12. Fesenko S, Jacob P, Alexakhin R, Sanzharova NI, Panov A, Fesenko G, Cecille $\mathrm{L}$ : Important factors governing exposure of the population and countermeasure application in rural settlements of the Russian Federation in the long-term after the Chernobyl accident. I Environ Radioact 200I, 56:77-98

13. Likhtarev IA, Kovgan LN, Vavilov SE, Perevoznikov ON, Litvinets LN, Anspaugh LR, Jacob P, Prohl G: Internal exposure from the ingestion of foods contaminated by I37Cs after the Chernobyl accident-report 2. Ingestion doses of the rural population of Ukraine up to 12 y after the accident (1986-1997). Health Phys 2000, 79:34I-57

\section{Pre-publication history}

The pre-publication history for this paper can be accessed here:

http://www.biomedcentral.com/content/backmatter/ 1476-069x-1-4-b1.pdf 